\title{
Aspectos sobre a etiopatogênese e terapêutica do vitiligo
}

\author{
Aspects of etiopathogenesis and therapy of vitiligo
}

\section{Ana Elisa Andrade Mendonça1, Daniela Dias Aquino', Juliana Andrade Mendonça Horbilon², Hermínio Maurício da Rocha Sobrinho ${ }^{3}$} Mendonça AEA, Aquino DD, Horbilon JAM, Rocha Sobrinho HMR. Aspectos sobre a etiopatogênese e terapêutica do vitiligo / Aspects
of etiopathogenesis and therapy of vitiligo. Rev Med (São Paulo). 2020 maio-jun.;99(3):278-85.

RESUMO: O vitiligo é uma doença cutânea crônica caracterizada por despigmentação da pele, sendo associada com desfiguração estética e considerável desconforto psicológico, representando grandes desafios em termos de cuidados dermatológicos. A partir do conhecimento do impacto psicossocial desta doença para o paciente e os desafios do seu tratamento pela medicina, este trabalho teve como objetivos destacar os principais aspectos etiopatogênicos do vitiligo, bem como, apresentar as opções terapêuticas atuais para o manejo da doença. Método: Revisão bibliográfica narrativa, utilizando-se as bases de dados Pubmed (US National Library of Medicine) e Portal Capes. A busca dos trabalhos foi realizada no ano de 2018, utilizando-se os seguintes Descritores em Ciências da Saúde: Vitiligo; Autoimunidade; Repigmentação; Tratamento Farmacológico; Fototerapia; Cosméticos; Cirurgia; Enxerto de tecido. Foram selecionados 26 artigos publicados no período de 2011 a 2018 que apresentaram conteúdos relacionados aos objetivos deste estudo. Resultados: $\mathrm{O}$ vitiligo desenvolve-se pela associação da predisposição genética e exposição a fatores ambientais. $\mathrm{O}$ tratamento tem o objetivo de limitar a progressão da doença, promover repigmentação das áreas afetadas e prevenir recidivas; podendo ser dividido em clínico, estético e cirúrgico. Os medicamentos tópicos, os sistêmicos, a fototerapia e os recentes imunobiológicos constituem tratamentos clínicos. O tratamento estético é representado pela camuflagem cosmética e o cirúrgico é indicado para aqueles que apresentam doença estável não responsiva a terapia clínica. Conclusão: $\mathrm{O}$ tratamento em geral é realizado pela associação de terapias, razão pela qual deve ser individualizado para cada paciente. O início precoce do tratamento está associado a um prognóstico mais favorável. Torna-se de extrema importância não negligenciálo além de conhecer inovações terapêuticas, tendo em vista o potencial estigmatizante da doença; melhorando assim a prática clínica e a qualidade de vida dos pacientes.

Descritores: Vitiligo; Autoimunidade; Repigmentação; Tratamento farmacológico; Fototerapia; Cosméticos; Cirurgia; Enxerto de tecido.

\begin{abstract}
Introduction: Vitiligo is a chronic skin disease characterized by cutaneous depigmentation, being associated with aesthetic disfiguration and considerable psychological discomfort, representing great challenges in terms of dermatological care. Main Objective: To address the etiopathogenic aspects of vitiligo, as well as to present current therapeutic options for disease management. Method: Narrative bibliographic review using the electronic Pubmed database (US National Library of Medicine). The research was carried out in 2018, using the following identifiers in Health Sciences: vitiligo, cosmetic camouflage and vitiligo, treatment and vitiligo, physiopathology and vitiligo, immunopathology and vitiligo. We selected 26 researches published in the period from 2011 to 2018 that presented contents related to the objectives of this study. Result: Vitiligo is developed by the association of a genetic predisposition and exposure to environmental factors. The treatment aims to limit the progression of the disease, promote repigmentation of the affected areas and prevent relapses; It can be divided into clinical, aesthetic and surgical. Topical, systemic, phototherapy and recent immunobiological medicines are clinical treatments. The aesthetic treatment is represented by cosmetic camouflage and the surgical one is indicated for those who present stable disease not responsive to clinical therapy. Conclusion: Treatment is usually performed by the association of techniques, which is why it should be individualized for each patient. Early initiation of treatment is associated with a more favorable prognosis of the disease. It is of extreme importance not to neglect it in addition to knowing therapeutic innovations, considering the potential societal stigmatization of the disease, as a result improving clinical practice and quality of life of patients.
\end{abstract}

Keywords: Vitiligo; Autoimmunity; Repigmentation; Drug therapy; Phototherapy; Cosmetic; Surgery; Tissue graft.

1. Pontifícia Universidade Católica de Goiás - PUC Goiás, Escola de Ciências Médicas, Farmacêuticas e Biomédicas, Graduação em Medicina, Goiânia - GO. ORCID: Mendonça AEA - https://orcid.org/0000-0002-0106-7405; Aquino DD - https://orcid.org/0000-0002-1515-5887. Email: anaelisam@ hotmail.com, dani93aquino@hotmail.com.

2. Médica Dermatologista pelo Hospital das Clínicas da USP. ORCID: https://orcid.org/0000-0002-5158-6879. Email: julianaamhorbilon@gmail.com.

3. Pontifícia Universidade Católica de Goiás - PUC Goiás. Professor Assistente da Graduação em Medicina da Escola de Ciências Médicas, Farmacêuticas e Biomédicas, Goiânia - GO. Doutor em Medicina Tropical e Saúde Pública. ORCID: https://orcid.org/0000-0002-7521-3700. Email: herminio. sobrinho@gmail.com.

Endereço para correspondência: Hermínio Maurício da Rocha Sobrinho. Rua 235, Setor Leste Universitário, Escola de Ciências Médicas, Farmacêuticas e Biomédicas, Área IV, PUC Goiás, Goiânia - GO. CEP: 74.605-050. Email: herminio.sobrinho@gmail.com 


\section{INTRODUÇÃO}

$\mathrm{V}$ itiligo é uma doença cutânea crônica autoimune, sendo considerada a desordem mais comum de despigmentação da pele ${ }^{1}$. É uma afecção que cursa com uma perda da pigmentação adquirida, caracterizada histologicamente pela ausência ou inatividade dos melanócitos epidérmicos ${ }^{2}$. Acomete aproximadamente $0,5 \%$ da população mundial. No Brasil essa doença ocorre em $1,2 \%$ das pessoas brancas e em $1,9 \%$ das pardas/negras, aparecendo entre as 25 doenças dermatológicas mais frequentes em todas as macrorregiões do país ${ }^{3}$. Os dois sexos são acometidos igualmente, e não há diferença em relação à cor da pele e raça. Pode se desenvolver em qualquer idade, entretanto, a maioria dos pacientes iniciam os sintomas antes dos 20 anos $^{2}$.

A patogênese desta doença é multifatorial, destacando-se fatores como a predisposição genética, fatores ambientais, stress oxidativo celular, alterações imunológicas ${ }^{4}$. É classificado em segmentar e não segmentar conforme sua localização na pele e progressão da doença ${ }^{1}$.

O tratamento do vitiligo engloba terapias clínicas, estéticas e cirúrgicas que visam limitar a progressão da doença, promover a repigmentação das áreas afetadas e prevenir recidivas 5 . No tratamento clínico dos pacientes encontram-se várias opções terapêuticas, dentre elas, medicamentos tópicos, corticoides orais, imunobiológicos e fototerapia ${ }^{6}$. A escolha da melhor abordagem clinica depende da extensão da lesão e da estabilidade da doença. O tratamento estético com a camuflagem cosmética é complementar às outras modalidades, visando melhora da qualidade de vida dos pacientes ${ }^{5}$. O tratamento cirúrgico é indicado para doença estável não responsiva a tratamento clínico. Dentre os tratamentos cirúrgicos, o transplante de melanócitos ganhou popularidade nos últimos anos ${ }^{7}$.

Compreender a patogênese do vitiligo, as opções disponíveis e emergentes de tratamento e sua contribuição para a autoestima e melhora da qualidade de vida do paciente é fundamental para aprimorar o manejo desta patologia. Diante disso, este estudo aborda os principais mecanismos etiopatogênicos do vitiligo e apresenta as possibilidades de tratamento disponíveis e eficazes, nos dias atuais, para esta patologia.

\section{MÉTODOS}

Trata-se de uma revisão bibliográfica narrativa, utilizando-se as bases de dados eletrônicas Pubmed (US National Library of Medicine) e Portal CAPES. A busca dos trabalhos foi realizada no período de janeiro a dezembro do ano de 2018, em língua portuguesa e inglesa, com o uso de Descritores em Ciências da Saúde, de forma isolada ou combinada: Vitiligo; Autoimunidade;
Repigmentação; Tratamento Farmacológico; Fototerapia; Cosméticos; Cirurgia; Enxerto de Tecido. Foram avaliados e selecionados artigos publicados no período de 2011 a 2018. O foco principal deste estudo foi a abordagem dos tratamentos atuais disponíveis para o vitiligo. Do material pesquisado e encontrado, foram selecionados 26 artigos que, realmente, apresentaram conteúdos que contribuíram para o cumprimento dos objetivos, da relevância e da atualidade do presente estudo. Nessa busca, foram excluídos da pesquisa os artigos publicados antes do ano de 2011, os que se encontravam duplicados e/ou indisponíveis, bem como aqueles cujos textos/conteúdos não correspondiam ao tema em estudo.

\section{RESULTADOS}

A partir da pesquisa nos bancos de dados utilizados, obtivemos um total de 98 artigos. Destes, três eram duplicatas, 49 foram eliminados na análise do resumo e pela leitura do conteúdo e 20 deles apresentavam indisponibilidade do texto completo. Ao final das exclusões, permaneceram 26 artigos para a realização do presente trabalho.

Esta revisão aborda, de forma narrativa, os principais aspectos etiopatogênicos e clínicos da doença e as possibilidades terapêuticas atuais para o manejo adequado de pacientes portadores do vitiligo segundo evidências encontradas em estudos individuais.

\section{DISCUSSÃO}

\section{Etiopatogenia do Vitiligo}

Devido à natureza multifatorial e ao envolvimento de múltiplos genes, a etiologia do vitiligo é bastante complexa e ainda restam muitos aspectos a serem desvendados. A predisposição genética é um dos fatores envolvidos na gênese da doença, sendo que parentes de primeiro grau tem $6-8 \%$ de risco de desenvolver vitiligo e ainda, a concordância em gêmeos monozigóticos é de aproximadamente $23 \%^{2}$. Os genes candidatos para o desenvolvimento da doença são HLA, AIRE, VIT1, CAT, FOXD3, ESR1, COMT, PTPN22, NALP1, PDGFRA, MYG1, MITF, CD117, XBP1, FAS, COX2, EDN1 e $\mathrm{ACE}$; podendo estar localizados em vários cromossomos, dentre eles os cromossomos 1, 2, 4, 6, 7, 8, 9, 14, 17, 19, 21 e $22^{2}$.

Estudos sugerem que os melanócitos de pacientes com vitiligo apresentam defeitos intrínsecos que reduzem sua capacidade de gerenciar o estresse celular, tornandoos mais vulneráveis a fatores estressores constantes como a radiação ultravioleta e vários produtos químicos ${ }^{4,8}$.

Na patogênese do vitiligo mecanismos autoimunes, genéticos e fatores ambientais provavelmente atuam em combinação levando à ausência de melanina nas 
áreas afetadas, sendo considerados gatilhos para alterar a imunidade e induzir a produção de autoanticorpos e formação de linfócitos T CD8+ que levam à destruição de melanócitos ${ }^{8,9}$. Os fatores ambientais mais citados na literatura são alterações hormonais, traumas, estresse psicológico, puberdade, gravidez, dieta e mudanças no estilo de vida ${ }^{9}$.

\section{Classificação}

O vitiligo pode ser classificado em segmentar e não segmentar, conforme sua localização na pele. $\mathrm{O}$ vitiligo não segmentar acomete 85 a $90 \%$ dos pacientes, é caracterizado pela presença de máculas brancas envolvendo várias partes do corpo bilateralmente, apresentando, na maioria das vezes, um padrão simétrico das lesões ${ }^{1}$. Apresenta curso crônico, com progressão contínua das lesões durante a vida ${ }^{2}$.

Já a forma segmentar, acomete 10 a $15 \%$ dos pacientes, é caracterizada pela despigmentação em apenas um lado do corpo, geralmente respeitando os limites da linha média ${ }^{1}$. Nessa forma de apresentação, a doença apresenta um início rápido, variando de dias a semanas, e geralmente apresenta estabilização em 1 a 2 anos $^{2}$.

\section{Aspecto psicossomático do vitiligo}

A estigmatização da doença faz com que pacientes com vitiligo geralmente apresentem uma autoimagem negativa e baixa autoestima, o que leva a um prejuízo na vida social do indivíduo, principalmente no sexo feminino e em adolescentes e adultos jovens ${ }^{10}$.

Estudo demonstra que $88 \%$ dos acometidos pela doença apresentaram alguma queixa psicológica: como o medo das lesões se espalharem (71\%), vergonha $(57 \%)$, insegurança $(55 \%)$, tristeza $(55 \%)$, inibição (53\%), descontentamento (50\%), impaciência (43\%), irritabilidade (36\%), infelicidade (35\%), imagem negativa para os outros $(35 \%)$, raiva $(26 \%)$, amargura $(25 \%)$, falta de autoconfiança $(25 \%)$, nojo de si mesmo (18\%) e outros $(16 \%)^{11}$.

A literatura evidencia alta associação entre vitiligo e o desenvolvimento de doenças psiquiátricas, em destaque a depressão, acometendo $35 \%$ dos pacientes no Reino Unido e $25 \%$ na India. Além disso, cerca de 25\% dos pacientes relatam que o vitiligo interfere diretamente em suas atividades sexuais e relacionamentos afetivos ${ }^{11}$.

O tratamento das lesões, por conseguinte, interfere diretamente na qualidade de vida desses pacientes, nas diversas esferas de relacionamento e até mesmo na vida profissional $^{10}$.

\section{Tratamento clínico}

As opções de tratamento incluem fármacos tópicos, fármacos orais e técnicas de fototerapia para o vitiligo, entretanto, nenhum destes tratamentos ocasiona a cura da doença ${ }^{6}$. Para o vitiligo segmentar, que afeta pequenas áreas do corpo, são recomendados medicamentos tópicos e fototerapia com Excimer Laser. Já no vitiligo generalizado é indicada fototerapia com os métodos Psoralen Plus Ultraviolet A (PUVA) e Narrowband Ultraviolet B (NBUVB) ${ }^{6}$.

\section{Tratamento farmacológico com medicamentos tópicos}

Os inibidores tópicos da calcineurina como o Tracrolimus e Pimecrolimus, podem ser utilizados como tratamento tópico de primeira linha para o vitiligo segmentar ${ }^{7}$. A repigmentação ocorre principalmente pelo mecanismo inibitório da ativação dos linfócitos $\mathrm{T}$, além de exercer efeito direto na migração e diferenciação de melanócitos durante a repigmentação ${ }^{12}$. Estudos sugerem que a associação do tacrolimus com a fototerapia NBUVB ou com o Laser Excimer apresentam resultados melhores quando comparados com o uso isolado dos métodos de fototerapia ${ }^{13}$.

Os corticosteroides tópicos como o Clobetasol também são úteis no tratamento de lesões pequenas do vitiligo segmentar, agindo na diferenciação dos melanócitos ${ }^{12}$. Apresentam alguns efeitos adversos como atrofia epidérmica, acne induzida por corticoides, rosácea, telangiectasias, equimoses e estrias, sendo que, aqueles pacientes tratados com corticosteroides mais potentes possuem maior risco de atrofia ${ }^{5}$. Dessa forma, lesões localizadas na face, pescoço e áreas intertriginosas devem ser tratadas com corticoides de média potência enquanto no restante do corpo, corticoides de alta potência ${ }^{7}$.

Os análogos da vitamina $\mathrm{D}$ também podem ser utilizados no tratamento do vitiligo, pois inibem a ativação de células $T$, mas não apresentam efeito relevante na repigmentação quando usados de forma isolada ${ }^{12}$. A eficácia terapêutica ocorre quando o medicamento é combinado com fototerapia ou com corticoides tópicos ${ }^{12}$.

\section{Tratamento farmacológico com medicamentos sistêmicos}

Os corticoides orais são eficazes no tratamento do vitiligo por agir na estabilização da doença, sendo indicados também na doença progressiva, em atividade, com o objetivo de reduzir o dano imunomediado aos melanócitos ${ }^{7}$. Apresentam vários efeitos colaterais, incluindo ganho de peso, insônia, acne, irregularidade do ciclo menstrual e hipertricose ${ }^{7}$. Relatos de descontinuação do tratamento pelos efeitos adversos são comuns ${ }^{5}$.

\section{Imunobiológicos - bloqueio da interleucina 17 (IL- 17A) e de seu receptor em melanócitos}

Estudos apontam o papel crítico da IL-17, uma quimiocina pró-inflamatória, com o surgimento de 
doenças autoimunes inflamatórias. Com relação ao vitiligo, a superexpressão dessa quimiocina pode modular o crescimento, a manutenção e a produção de pigmentos dos melanócitos, suprimindo a pigmentação por atuar na via de regulação negativa dos genes envolvidos ${ }^{14}$.

Ao inibir essa quimiocina ou seu receptor (IL-17R) com anticorpos monoclonais reverte-se o efeito bloqueador da melanogênese. O bloqueio da IL-17A resultou na prevenção da morte celular, bem como na expressão dos genes necessários para a sobrevivência dos melancólicos, sendo restaurada a produção de melanina ${ }^{15}$. Entre os medicamentos imunobiológicos inibidores da IL17 destacam-se o secuquinumabe, ixekizumabe e brodalumabe. $\mathrm{O}$ secuquinumabe e o ixekizumabe são anticorpos que têm como alvo a IL-17A em si, em contraste com o brodalumabe, que atua se ligando ao receptor da IL-17A (IL-17RA), bloqueando assim as ações dessa quimiocina ${ }^{14,15}$.

Isso sugeriu uma estratégia promissora contra a perda de melanócitos no vitiligo, utilizando terapias biológicas sistêmicas que visem quimiocinas específicas presentes no curso da doença ${ }^{15}$.

\section{Bloqueio da Janus Kinase}

A Janus Kinase (JAK) participa do processo de transcrição e translocação de genes envolvidos na despigmentação da pele ${ }^{16}$. Estes genes são dependentes de IFN- $\gamma$ que quando se liga ao seu receptor ativa-se a via da JAK, que leva a secreção de citocinas como CXCL9 e CXCL10, responsáveis pelo recrutamento de células T $\mathrm{CD} 8+$ autorreativas para a pele que atacam os melanócitos e levam a despigmentação ${ }^{16}$. Como proposta terapeutica que iniba esse processo, o Tofacitinibe e o Ruxolitinibe agem bloqueando a sinalização da JAK e o consequente recrutamento e destruição dos melanócitos ${ }^{16}$.

Observa-se que áreas expostas ao sol obtiveram melhor resposta com o uso dessa modalidade de tratamento, visto que a pigmentação depende da fotoativação, estimulando os melanócitos a migrarem para a epiderme ${ }^{17}$.

\section{Fototerapia}

A Psoralen Plus Ultraviolet A (PUVA) foi o primeiro método de fototerapia utilizado no tratamento do vitiligo. É realizada com a ingestão de um medicamento fotossensibilizador e em seguida, o paciente é exposto à radiação UVA com comprimentos de onda de 320 a 400 $\mathrm{nm}^{18}$. Possui efeitos adversos como náuseas e vômitos, além de um risco aumentado no desenvolvimento de câncer de pele ${ }^{19}$.

Dessa forma, essa técnica vem sendo gradualmente substituída pela Narrowband Ultraviolet B (NB-UVB), que além de apresentar menos efeitos adversos, possui maior eficiência ${ }^{18}$. Em estudo realizado, a resposta global ao tratamento com fototerapia PUVA foi inferior à do
NB-UVB, corroborando com dados de outras pesquisas já realizadas ${ }^{6}$. Hoje, o NB-UVB é considerado a primeira linha no tratamento clínico do vitiligo generalizado ${ }^{20}$.

A fototerapia NB-UVB é caracterizada por emissão de luz policromática com comprimento de onda de pico de 311 a $313 \mathrm{~nm}$, agindo na repigmentação da lesão devido à estimulação de melanócitos funcionais na pele perilesional ou melanócitos imaturos nos folículos pilosos no vitiligo estável $^{18}$. Já no vitiligo não estável, ela age inibindo a atividade de linfócitos $\mathrm{T}$ autorreativos, diminuindo a progressão da doença ${ }^{18}$.

O tratamento combinado da NB-UVB com inibidores tópicos da calcineurina, análogos tópicos da vitamina $\mathrm{D}$ e outros medicamentos têm apresentado bons resultados, mostrando sinergismo para maior eficácia e diminuindo o tempo de duração da fototerapia ${ }^{20}$.

O Laser Excimer com comprimento de onda de $308 \mathrm{~nm}$, atualmente é considerado um método eficaz para o tratamento do vitiligo localizado ${ }^{5}$. O Laser age na repigmentação pela indução de apoptose de células $\mathrm{T}$ e também pela estimulação de proliferação e migração de melanócitos imaturos ${ }^{18}$. Ele permite aplicação de alta intensidade de radiação em áreas específicas da pele, poupando a superfície que não apresenta hipopigmentação, e dessa forma, prevenindo a hiperpigmentação da pele sadia adjacente à lesão $0^{21}$.

\section{Tratamento estético - camuflagem cosmética}

A camuflagem cosmética refere-se à técnica em que se utilizam cremes, bases, corretivos e outros cosméticos com o intuito de repigmetar, temporariamente ou definitivamente as regiões afetadas pelo vitiligo. É atualmente, utilizada para amenizar cicatrizes, imperfeições e anormalidades pigmentares cutâneas, incluindo o vitiligo $0^{22}$.

As técnicas de camuflagem podem ser especialmente úteis em pacientes que não conseguem completo ou imediato resultado em outras modalidades de tratamento, como os clínicos e cirúrgicos, visto que é uma modalidade mais acessível, simples, não invasiva, facilmente reprodutível, de resultado imediato e que não pretende substituir as outras formas de tratamento, mas complementá-las. Nesses casos a maquiagem corretiva pode ser de grande importância para minimizar o impacto desta afecção cutânea sobre a qualidade de vida dos pacientes $^{23}$.

No estudo de Padilla-España et al..$^{10}$, foi avaliado o impacto positivo do tratamento com camuflagem cosmética na qualidade de vida dos pacientes através do questionário Children Dermatology Quality Index (cDLQI). Após sessões de tratamento com objetivo tanto prático quanto didático o questionário foi reaplicado, demonstrando uma melhora significante na qualidade de vida dos participantes ${ }^{10}$. 


\section{Tipos de Camuflagem}

\section{Bases de cobertura}

Estas são consideradas os mais comuns e melhores disponíveis para fins de camuflagem. Os produtos contêm tipicamente até $25 \%$ a mais de pigmento em comparação com a maquiagem normal, são à prova d'água e é necessária uma única aplicação ao $\operatorname{dia}^{22}$. O emulsificante primário é geralmente a trietanolamina ou um surfactante não iônico e o secundário é geralmente estearato de glicerina ou estearato de propilenoglicol. Como limitação encontra-se a dificuldade de aplicar em uma área de superfície maior, alto custo, restrição do uso em pacientes com acne ou outras lesões ${ }^{22}$.

\section{Autobronzeadores}

Os produtos autobronzeadores têm sido utilizados de forma eficaz na camuflagem do vitiligo. Os mais comuns têm como princípio ativo a di-hidroxiacetona (DHA) que reage com proteínas no estrato córneo para formar as chamadas melanoidinas, as quais darão à pele a coloração desejada, durando cerca de 10 dias. A concentração de DHA necessária é maior nas pessoas de pele mais escura ${ }^{22}$.

A DHA também possui propriedades de proteção solar, porém baixa comparada aos protetores recomendados e tende a diminuir a cada dia após a aplicação. Dentre as desvantagens encontram-se: a dificuldade em obter a cor desejada e uniformizá-la com a pele circundante, o potencial em causar alergias e dermatites, danos ao DNA e mutações nos queratinócitos ${ }^{22}$.

\section{Micropigmentação}

Micropigmentação, dermatografia ou tatuagem médica trata-se de uma tatuagem com fins cosméticos e medicinais, garantindo uma camuflagem permanente em diversas doenças dermatológicas. Muito utilizada também no acabamento de cirurgias craniofaciais e reconstruções mamárias $^{22}$.

O procedimento está associado com alta satisfação dos pacientes e baixas taxas de complicação, tendo melhores resultados em peles mais escuras. No vitiligo, está indicada na doença resistente a outros tratamentos, estável e localizado ${ }^{22}$.

Dentre as vantagens dessa modalidade de tratamento encontra-se o resultado rápido e instantâneo, custo relativamente baixo e a possibilidade de ser usada na região de pálpebras, onde outros métodos não podem ser utilizados. Como desvantagens e limitações estão a dificuldade em obter uma correspondência exata de cores, a despigmentação gradual, alergias de contato e o risco de transmissão de doenças infecciosas. Os efeitos adversos imediatos geralmente resultam de técnica inadequada e falta de adesão à assepsia. Estes incluem: equimoses, crostas, edema e infecção bacteriana secundária ${ }^{22}$.

\section{Tratamento Cirúrgico}

O tratamento cirúrgico do vitiligo foi relatado pela primeira vez em 1947 e, apartir desse período, as técnicas cirúgicas estão se tornando cada vez mais variadas e sofisticadas ${ }^{24}$.

São indicadas diante da estabilidade da doença, sendo que, o vitiligo é considerado estável quando não há surgimento de novas lesões em um período de seis meses a dois anos ${ }^{7}$. O vitiligo segmentar é o que mais se beneficia das técnicas cirúrgicas, obtendo uma resposta extremamente favorável. Lesões em áreas do corpo que apresentam maior oferta vascular e densidade folicular, como cabeça e pescoço, apresentam maior chance de sucesso na cirurgia quando comparadas com lesões em extremidades $^{24}$.

As opções de tratamento cirúrgico podem ser divididas em métodos de enxerto tecidual e métodos de enxerto celular ${ }^{25}$. O método de enxerto tecidual envolve o transplante de tecido do próprio paciente para o síto da lesão, dessa forma, sendo ideal para o tratamento de áreas pequenas $^{24}$. Possui a vantagem de ser um procedimento de baixo custo, não demanda equipamentos sofisticados, apresenta boa eficácia, com uma combinação uniforme das cores e baixa risco de cicatrizes ${ }^{7}$.

O método de enxerto celular envolve a criação de uma suspensão celular de um enxerto de pele fina a ultrafina ${ }^{24}$. Hoje, a suspensão epidermica não cultivada, também conhecida como transplante de melanócitos, é realizada mais frequentemente e é considerada padrão ouro de enxerto para vitiligo ${ }^{7}$.

O procedimento de transplante de melanócitos envolve inicialmente a obtenção de uma amostra de pele de uma área normalmente pigmentada, sendo que o couro cabeludo, a região glútea e a coxa são frequentemente usados $^{25}$. A amostra é mergulhada em ácido tripsinaetilenodiaminotetracético (EDTA) e depois incubada por período de 60 minutos. Em seguida, a epiderme é separada, centrifugada e suspensa em solução para isolar uma amostra de suspensão celular contendo melanócitos e queratinócitos ${ }^{25}$. É necessário preparar a área receptora com o debridamento até a junção dermo-epidérmica, e em seguida aplicar a suspensão na área desnudada com o uso de uma seringa. A área é coberta com colágeno e curativo, que permanece por 4 a $7 \operatorname{dias}^{26}$.

O algorítimo do tratamento do vitiligo está ilustrado nas Figuras 1 e 2. 


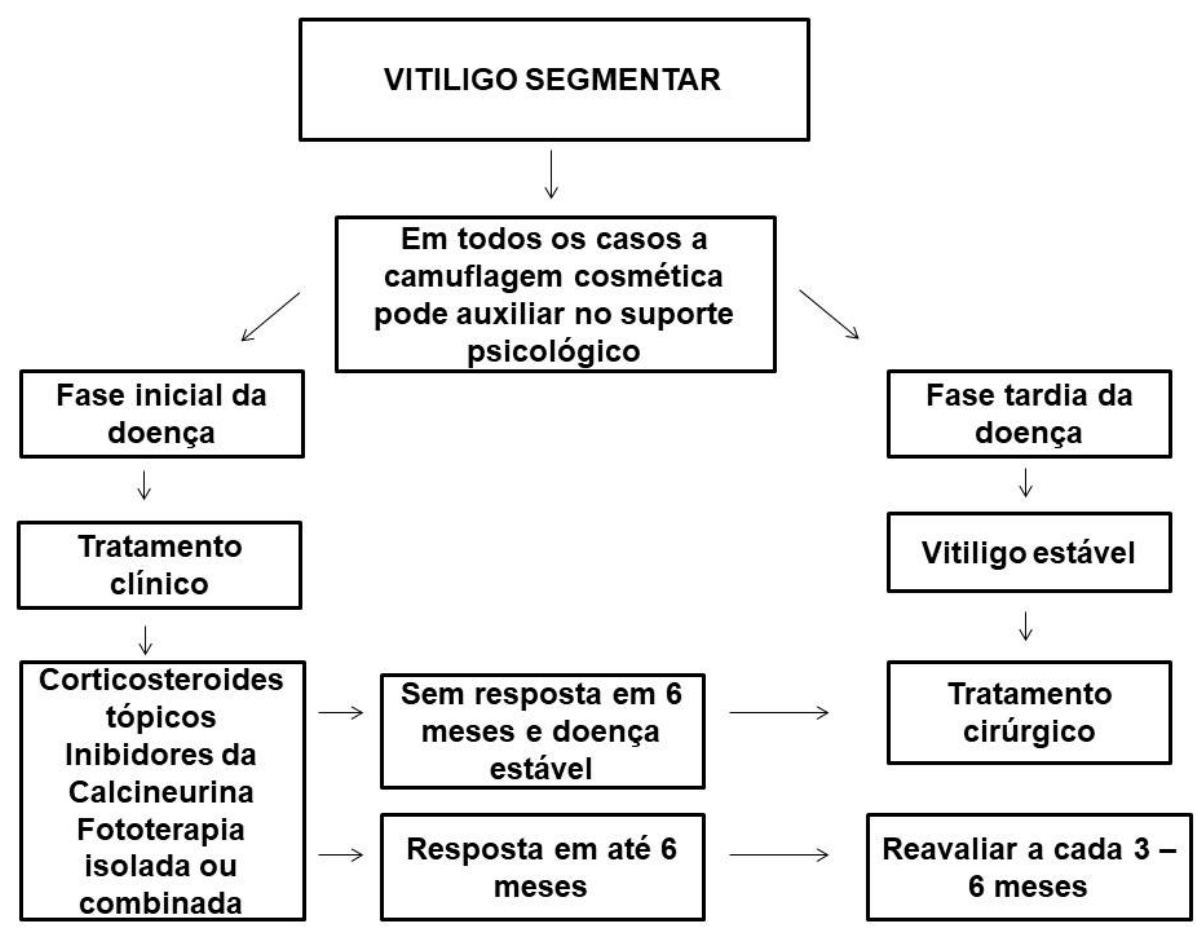

Fonte: Adaptado de Passeron ${ }^{5}$, Rodrigues ${ }^{7}$.

Figura 1: Algoritimo do tratamento do vitiligo segmentar

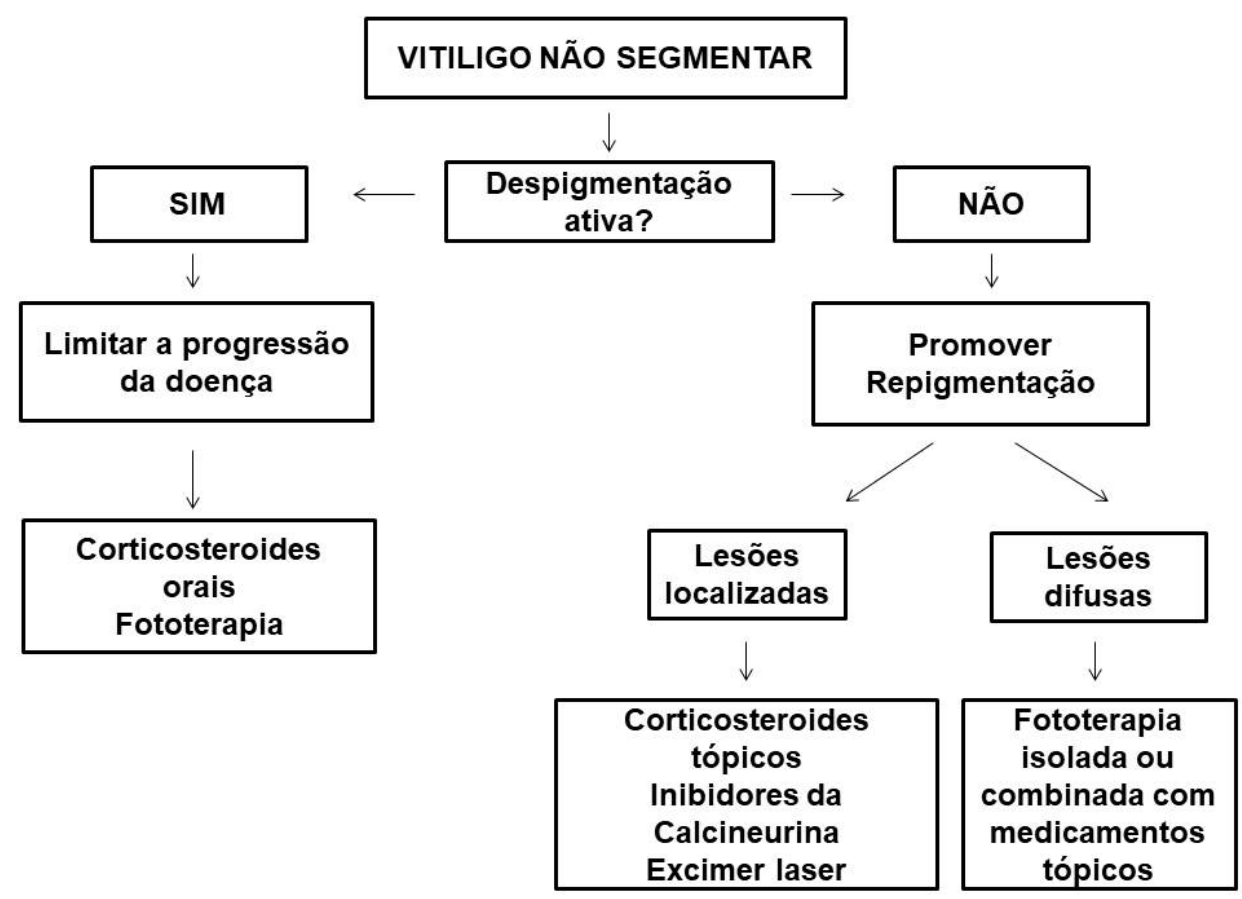

Fonte: Adaptado de Passeron ${ }^{5}$, Rodrigues ${ }^{7}$

Figura 2: Algoritimo do tratamento do vitiligo não segmentar

\section{CONCLUSÃO}

Existem vários tratamentos disponíveis e eficazes para o vitiligo, englobando as modalidades clínica, estética e cirúrgica. Dentre esses, terapias inovadoras e promissoras como o uso de imunobiológicos, que agem inibindo mediadores específicos na gênese da doença, e o transplante de melanócitos, um enxerto de suspensão 
celular que age na repigmentação da área afetada.

Até o momento não há cura para o vitiligo e nenhum método eficaz para limitar a disseminação da doença. O tratamento, às vezes insatisfatório, visa controlar o processo inflamatório/autoimune e estimular a repigmentação cutânea.

Técnicas de camuflagem adequadamente aplicadas podem promover uma melhora considerável no aspecto da lesão, aumentando a autoestima e a qualidade de vida.

A associação entre estas modalidades faz-se necessária, visto que otimiza-se o resultado final das lesões e possibilita um maior grau de satisfação do paciente. Estudos destacam que tratamentos combinados oferecem maior chance de repigmentação cutânea bem sucedida.

Em geral, o tratamento é prolongado, razão pela qual se deve avaliar individualmente o paciente e considerar os riscos e benefícios de cada opção terapêutica, minimizando seus os efeitos colaterais.

Por não haver perda da capacidade funcional, o vitiligo é abordado por muitos profissionais como algo unicamente estético. Aconscientização sobre a importância do diagnóstico precoce e novas modalidades de tratamento dessa afecção torna-se de extrema importância, tendo em vista a alta capacidade estigmatizante e o prejuízo social e psicológico gerado nos pacientes acometidos; possibilitando assim, melhorar o atendimento, a prática clínica e a qualidade de vida dos portadores dessa doença.

Participação dos autores: Mendonça AEA e Aquino DD: Idealização do estudo, pesquisa e obtenção dos dados, análise e interpretação, redação do manuscrito, revisão crítica do manuscrito. Sobrinho HMR e Horbilon JAM: Orientação, idealização do estudo, pesquisa e obtenção dos dados, análise e interpretação, redação do manuscrito, revisão crítica do manuscrito.

\section{REFERÊNCIAS}

1. Boniface K, Seneschal J, Picardo M, Taïeb A. Vitiligo: focus on clinical aspects, immunopathogenesis, and therapy. Clin Rev Allergy Immunol. 2018;54(1):52-67. doi: 10.1007/ s12016-017-8622-7.

2. Speeckaert R, van Geel N. Vitiligo: an update on pathophysiology and treatment options. Am J Clin Dermatol. 2017;18(6):733-44. doi: 10.1007/s40257-0170298-5.

3. Szabo I, Brandão ER. "Mata de tristeza!": representações sociais de pessoas com vitiligo atendidas na farmácia universitária da Universidade Federal do Rio de Janeiro, Brasil. Interface Commun Heal Educ. 2016;20(59):953-65. doi: 10.1590/1807-57622015.0596.

4. Rashighi M, Harris JE. Vitiligo pathogenesis and emerging treatments. Dermatol Clin. 2017;35(2):257-65. http:// dx.doi.org/10.1016/j.det.2016.11.014

5. Passeron T. Medical and maintenance treatments for vitiligo. Dermatol Clin. 2017;35(2):163-70. doi: 10.1016/j. det.2016.11.007.

6. Bae JM, Jung HM, Hong BY, Lee JH, Choi WJ, Lee JH, et al. Phototherapy for vitiligo: a systematic review and meta-analysis. JAMA Dermatol. 2017;153(7):666-74. doi: 10.1001/jamadermatol.2017.0002.

7. Rodrigues M, Ezzedine K, Hamzavi I, Pandya AG, Harris JE. Current and emerging treatments for vitiligo. J Am Acad Dermatol. 2017;77(1):17-29. http://dx.doi.org/10.1016/j. jaad.2016.11.010.

8. Rodrigues M, Ezzedine K, Hamzavi I, Pandya AG, Harris JE. New discoveries in the pathogenesis and classification of vitiligo. J Am Acad Dermatol. 2017;77(1):1-13. http:// dx.doi.org/10.1016/j.jaad.2016.10.048.

9. Patel S, Rauf A, Khan H, Meher BR, Hassan SSU. A holistic review on the autoimmune disease vitiligo with emphasis on the causal factors. Biomed Pharmacother. 2017;92:501-8. doi: 10.1016/j.biopha.2017.05.095.

10. Padilla-España L, Ramírez-López B, Fernández-Sánchez E. Utilidad del maquillaje terapéutico en niños con vitíligo en un taller coordinado por enfermería de dermatología. Enferm Clin. 2014;24(3):196-9. doi: 10.1016/j.enfcli.2014.03.001.

11. Cupertino F, Niemeyer-Corbellini JP, Ramos-e-Silva M. Psychosomatic aspects of vitiligo. Clin Dermatol. 2017;35(3):292-7. http://dx.doi.org/10.1016/j. clindermatol.2017.01.001

12. Birlea SA, Goldstein NB, Norris DA. Repigmentation through Melanocyte regeneration in vitiligo. Dermatol Clin. 2017;35(2):205-18. doi: 10.1016/j.det.2016.11.015.

13. Wong R, Lin AN. Pharmacology and therapeutics efficacy of topical calcineurin inhibitors in vitiligo. Int J Dermatol. 2013;52(4):491-6. doi: 10.1111/j.1365-4632.2012.05697.x.

14. Singh RK, Lee KM, Vujkovic-cvijin I, Ucmak D, Farahnik $\mathrm{B}$, Abrouk M, et al. The role of IL-17 in vitiligo: a review. Autoimmun Rev. 2016;15(4):397-404. doi: 10.1016/j. autrev.2016.01.004.

15. Bhardwaj S, Bhatia A, Kumaran MS, Parsad D. Role of IL-17A receptor blocking in melanocytes survival: A strategic intervention against vitiligo. Exp Dermatol. 2019;28(6):682-9. doi: 10.1111/exd.13773.

16. Rashighi M, Harris JE. Interfering with the IFN-gamma/ CXCL10 pathway to develop new targeted treatments for vitiligo. Ann Transl Med. 2015;3(21):343. doi: 10.3978/j. issn.2305-5839.2015.11.36.

17. Le Poole IC, Mehrotra S. Replenishing regulatory $\mathrm{T}$ cells to halt depigmentation in vitiligo. J Investig Dermatology Symp Proc. 2017;18(2):S38-45. doi: 10.1016/j.jisp.2016.10.023

18. Esmat S, Hegazy RA, Shalaby S, Chu-Sung $\mathrm{Hu}$ S, Lan CCE. Phototherapy and combination therapies for vitiligo. Dermatol Clin. 2017;35(2):171-92. http://dx.doi. 
org/10.1016/j.det.2016.11.008.

19. Ibbotson SH. A Perspective on the use of NB-UVB phototherapy vs. PUVA photochemotherapy. Front Med. 2018;5(July):1-8. doi: 10.3389/fmed.2018.00184.

20. Yazdani Abyaneh M, Griffith RD, Falto-Aizpurua L, Nouri $\mathrm{K}$. Narrowband ultraviolet B phototherapy in combination with other therapies for vitiligo: mechanisms and efficacies. J Eur Acad Dermatology Venereol. 2014;28(12):1610-22. doi: $10.1111 / j d v .12619$.

21. Antonio CR, Antonio JR, De Vita Marques AM. Excimer laser no tratamento do vitiligo em 123 pacientes: estudo retrospectivo. Surg Cosmet Dermatol. 2011;3(3):213-8. Disponível em: http://www.surgicalcosmetic.org.br/detalheartigo/148/Excimer-Laser-no-tratamento-do-vitiligo-em123-pacientes--estudo-retrospectivo.

22. Kaliyadan F, Kumar A. Camouflage for patients with vitiligo. Indian J Dermatol Venereol Leprol. 2012;78(1):8. . doi: 10.4103/0378-6323.90940.
23. Salsberg JM, Weinstein M, Shear N, Lee M, Pope E. Impact of cosmetic camouflage on the quality of life of children with skin disease and their families. J Cutan Med Surg. 2016;20(3):211-5. doi: 10.1177/1203475415595175.

24. Mohammad TF, Hamzavi IH. Surgical therapies for vitiligo. Dermatol Clin. 2017;35(2):193-203. http://dx.doi. org/10.1016/j.det.2016.11.009.

25. Vakharia PP, Lee DE, Khachemoune A. Efficacy and safety of noncultured melanocyte-keratinocyte transplant procedure for vitiligo and other leukodermas: a critical analysis of the evidence. Int J Dermatol. 2018;57(7):770-5. doi: 10.1111/ijd.13895.

26. Nahhas AF, Mohammad TF, Hamzavi IH. Vitiligo surgery: shuffling melanocytes. J Investig Dermatol Symp Proc. 2017;18(2):S34-7. https://doi.org/10.1016/j. jisp.2017.01.001.

Recebido: 29/03/2019

Aceito: 17/03/2020 